\title{
Fibrosis in hypertensive heart disease: role of the renin-angiotensin-aldosterone system
}

\author{
Arantxa González, BSc ${ }^{\mathrm{a}}$, Begoña López, $\mathrm{PhD}^{\mathrm{a}}$, \\ Javier Díez, MD, $\mathrm{PhD}^{\mathrm{a}, \mathrm{b}, *}$ \\ a Area of Cardiovascular Pathophysiology, Centre for Applied Medical Research, \\ University of Navarra, C. Irunlarrea 1, 31080 Pamplona, Spain \\ ${ }^{\mathrm{b}}$ Department of Cardiology and Cardiovascular Surgery, University Clinic, \\ School of Medicine, University of Navarra, Pamplona, Spain
}

Organs are composed of highly differentiated, very specialized parenchymal cells surrounded by stroma consisting of extracellular matrix, tissue fluid, and undifferentiated pluripotent mesenchymal cells. Parenchymal cells distinguish one organ from another based on their unique morphologic features and their highly specialized functions. Disproportionate stromal growth, relative to parenchymal growth, termed "fibrosis" (sclerosis or cirrhosis), represents a pathologic structural remodeling of an organ [1].

Fibrosis presents in several different morphologic patterns. A reparative (replacement) fibrosis appears at sites of parenchymal cell loss. For example, microscopic scarring of ventricular myocardium follows cardiac myocyte necrosis [2-4], whereas a macroscopic scar follows segmental infarction $[5,6]$. A perivascular fibrosis of intramural vessels with extensions into the contiguous interstitial space has been referred to as a "reactive fibrosis" because loss of parenchyma is not a requisite [7]. A perivascular-interstitial fibrosis, for example, accompanies chronic elevations in the effector hormones of the renin-angiotensin-aldosterone system [8-11].

Absolute fibrosis is defined as increased collagen concentration of an organ and consists predominantly of fibrillar collagen types I and III that appear secondary to altered collagen turnover (synthesis greater than degradation). Collectively, fibrosis is a common pathway to organ failure. This holds true for such diverse organs as the heart [12,13], kidneys [14,15], lungs [16,17], and liver [18].

\footnotetext{
* Corresponding author.

E-mail address: jadimar@unav.es (J. Díez).
} 
Under certain circumstances, a regression of fibrous tissue occurs after the repair process has been completed. This is related to fibrillar collagen degradation by matrix metalloproteinases $[19,20]$. In other cases, there is a persistent fibrosis (eg, infarct scar of the myocardium) that is essential for organ integrity. Lastly, a progressive fibrosis can occur (eg, experimental glomerulonephritis, chronic elevation of circulating angiotensin II [ANGII] or aldosterone) and destroys organ architecture and accounts for its failure [20-23]. The need to prevent fibrosis or to regress it, once formed, represents a major challenge. Various strategies can be taken [14].

\section{Myocardial fibrosis in hypertensive heart disease}

\section{Clinical evidence}

The essential criterion in defining hypertensive heart disease (HHD) is a greater than normal heart mass in the absence of a cause other than arterial hypertension. It is now accepted, however, that besides left ventricular hypertrophy (LVH), alterations in myocardial structure as listed below account for loss of tissue homogeneity and pathologic remodeling that appears in HHD:

\section{Cellular alterations}

Cardiomyocytes

Hypertrophy, atrophy, apoptosis, necrosis

Noncardiomyocytes

Hyperplasia and apoptosis of fibroblasts

Hypertrophy or hyperplasia of vascular smooth muscle cells

\section{Noncellular alterations}

Interstitial and perivascular fibrosis

Microscopic scarring

Medial thickening of coronary arterioles

Diminished number of capillaries

A growing body of evidence indicates that myocardial fibrosis is one of the key pathologic features of myocardial remodeling in HHD. In fact, a number of studies performed in postmortem human hearts [24-26] and endomyocardial human biopsies [27-30] have shown that myocardial collagen volume fraction, a morphometric measure of the amount of tissue collagen, is constantly increased in patients with HHD compared with normotensive controls (Fig. 1). Furthermore, an exaggerate accumulation of fibrillar collagen types I and III within the myocardial interstitium and surrounding intramural coronary arteries and arterioles has been evidenced immunohistochemically in patients with HHD [31].

\section{Potential mechanisms}

Collagen types I and III are the major fibrillar collagens produced by fibroblasts in the adult heart. They exhibit the characteristic triple helical 
$\mathbf{A}$

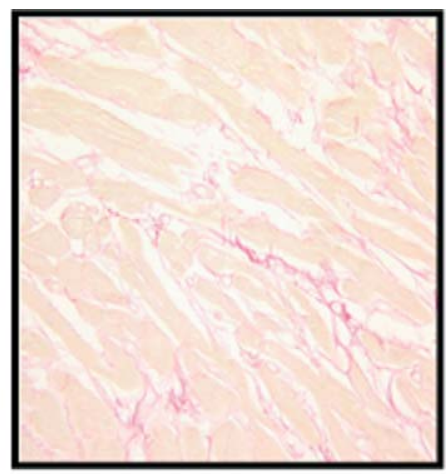

Normotensive

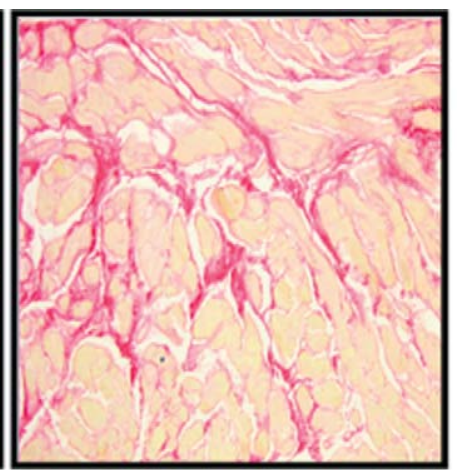

Hypertensive

B

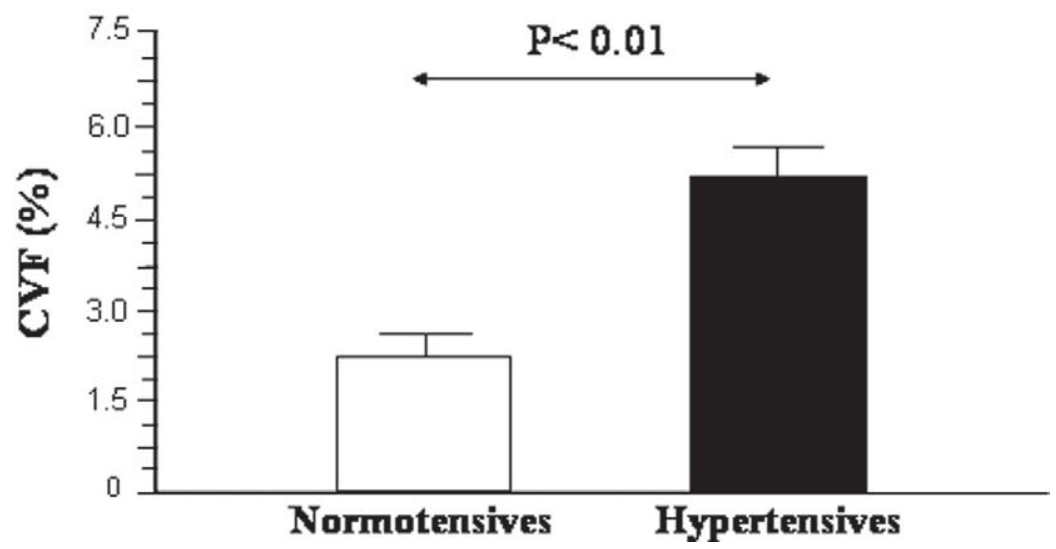

Fig. 1. (A) Histologic sections of interventricular septal specimen biopsies from humans. Sections were stained with picrosirius red, and the interstitial collagen was identified in red (original magnification $\times 20$ ). $(B)$ Collagen volume fraction $(\mathrm{CVF})$ determined in interventricular septal specimen biopsies from humans. (Adapted from Querejeta R, Varo N, López B, Larman M, Artiñano E, Etayo JC, et al. Serum carboxy-terminal propeptide of procollagen type I is a marker of myocardial fibrosis in hypertensive heart disease. Circulation 2000;101:1729-35; with permission.)

conformation formed by three polypeptide chains ( $\alpha$ chains). Fibrillar collagen of the heart provides the structural scaffolding for cardiomyocytes and coronary vessels and imparts cardiac tissue with physical properties that include stiffness and resistance to deformation [12]. In addition, fibrillar collagen may also act as a link between contractile element of adjacent cardiomyocytes and as a conduit of information that is necessary for cell function.

As in other organs, collagen turnover of normal adult heart results from the equilibrium between the synthesis and degradation of collagen types I and III molecules [32]. The synthesis of collagen molecules follows the 
normal pattern of protein synthesis, but it differs from the synthesis of many proteins in that the newly formed $\alpha$ chains undergo a number of posttranslational modifications. Extracellular degradation of collagen fibers is mediated by collagenase and other members of the matrix metalloproteinase family of zinc-containing endoproteinases. The active form of collagenase can be inhibited by interaction with naturally occurring specific tissue inhibitors of matrix metalloproteinases (TIMPs).

As shown by in vivo experiments, chronic pressure overload stimulates both procollagen gene expression and collagen protein synthesis leading to excessive collagen deposition and fibrosis [33]. In addition, in vitro studies have shown that procollagen type I synthesis is stimulated in cardiac fibroblasts submitted to cyclic mechanical load [33]. Hemodynamic overload of the left ventricle caused by systemic hypertension may play a role in myocardial fibrosis.

Nevertheless, two types of findings suggest that besides the mechanic factor, nonhemodynamic factors may also contribute to myocardial fibrosis in human hypertension. First, myocardial fibrosis has been found not only in the left ventricle but also in the right ventricle [25,34] and the interventricular septum [35] in postmortem studies of human hearts with HHD. Second, recent studies have shown that the ability of antihypertensive treatment to regress fibrosis in hypertensives with biopsy-proved myocardial fibrosis is independent of its antihypertensive efficacy [29,36]. The current view is that myocardial fibrosis may be the consequence of the loss of reciprocal regulation that normally exists between molecules that stimulate (eg, ANGII) and molecules that inhibit fibrillar collagen turnover [37]. Factors modulating collagen types I and III turnover in the myocardium include the following:

Factors that facilitate the synthesis of collagen

Vasoactive substances

Angiotensin II, endothelin-1, catecholamines

Growth factors

Transforming growth factor- $\beta_{1}$, platelet-derived growth factor, basic fibroblast growth factor, insulin-like growth factor-1

Hormones

Aldosterone, deoxycorticosterone

Cytokines

Interleukin-1

Adhesion molecules

Ostepontin

Factors that facilitate the degradation of collagen

Vasoactive substances

Bradykinin, prostaglandins, nitric oxide, natriuretic peptides

Growth factors

Hepatocyte growth factor 


\section{Hormones}

Glucocorticoids

Cytokines

Tumoral necrosis factor- $\alpha$, interferon- $\gamma$

Endogenous peptides

$\mathrm{N}$-acetyl-seryl-aspartyl-lysyl-proline

An excess of stimulators, caused by either absolute stimulator overproduction or by their relative overabundance because of a deficit in inhibitor formation can promote fibrosis.

\section{Clinical impact}

Several arguments support the concept that myocardial fibrosis has a particularly important influence in the process of heart failure associated with cardiac remodeling [38]. First, interstitial fibrosis contributes to ventricular wall stiffness and consequently impairs cardiac compliance, contributing to impaired diastolic function. Second, because neither the collagen network nor the fibroblasts contribute to systolic contraction, increased collagen deposition and fibroblast volume means that systolic work is being performed by a smaller proportion of the cardiac mass, contributing to systolic dysfunction. Third, perivascular fibrosis leads to increased distance that oxygen must diffuse and potentially lowers $\mathrm{PaO}_{2}$ for the working cardiomyocytes. Finally, electrical coupling on the cardiomyocytes may be impaired by the accumulation of collagen proteins and fibroblasts because such accumulation causes morphologic separation of cardiomyocytes.

\section{Role of angiotensin II in myocardial fibrosis}

Various lines of evidence support a role for ANGII as a critical candidate factor to induce myocardial fibrosis in HHD.

\section{In vivo evidence}

\section{Animal models}

Endogenous elevations in circulating ANGII that accompany unilateral renal artery stenosis [39] or the infusion of exogenous ANGII [40] are associated with increased blood pressure and fibrosis. The appearance of such fibrous tissue formation is preceded by increased expression of ANGII type $1\left(\mathrm{AT}_{1}\right)$ receptors, transforming growth factor- $\beta_{1}\left(\mathrm{TGF}-\beta_{1}\right)$, and mRNA for collagen types I and III [41]. In addition, development of fibrosis involves proliferating fibroblasts and cell differentiation into myofibroblasts [42]. Two observations suggest that the ability of ANGII to induce cardiac fibrosis in these models is independent of its hypertensive action. First, fibrosis in the renal artery stenosis model develops in both low-pressure right and left atria and right ventricle and high-pressure left ventricle [43]. 
Second, cardiac fibrosis in the ANGII infusion model can be prevented by either angiotensin converting enzyme (ACE) inhibitors or $\mathrm{AT}_{1}$ receptor antagonists, but not hydralazine or prazosin, despite a similar antihypertensive efficacy of these compounds [44,45]. The critical role of ANGII in hypertension-associated cardiac fibrosis is further supported by the observation that experimental infrarenal aortic binding, which does not induce ANGII, causes blood pressure elevation and cardiomyocyte hypertrophy but not cardiac fibrosis [43].

The hypertensive Ren2 rat provides a well-established model of ANGIIdependent cardiac hypertrophy [46]. Several studies have revealed that interstitial and perivascular fibrosis, along with extensive collagen types I and III deposition are present in Ren2 [47-49]. Increased cardiac renin and ANGII levels have been described in this transgenic rat model [46]. In addition, cardiac lesions are very sensitive to $\mathrm{ACE}$ inhibition and $\mathrm{AT}_{1}$ receptor antagonism in Ren2 rats [50]. As a result, the development of hypertrophy and fibrosis in the heart of these animals has been attributed, at least partially, to a local activation of the cardiac renin-angiotensin system.

\section{Pharmacologic studies}

Experimental findings. Pharmacologic interventions with ACE inhibitors or $\mathrm{AT}_{1}$ receptor antagonists have underscored the potential importance of ANGII in the mediation of cardiac fibrosis in pathologic conditions, such as primary hypertension. In rats with spontaneous hypertension and LVH, myocardial fibrosis has been shown to regress by treatment with the ACE inhibitor lisinopril [51]. This effect occurred independently of the drug's antihypertensive effect [51]. It has been found that chronic $\mathrm{AT}_{1}$ receptor antagonism with losartan resulted in reversal of fibrosis, inhibition of the posttranscriptional synthesis of procollagen type I, inhibition of TIMP-1 expression, and stimulation of collagenase activity in the left ventricle of adult rats with spontaneous hypertension $[52,53]$. Analysis of the individual data showed that the intensity of these myocardial changes was independent of the antihypertensive efficacy of the drug $[52,53]$.

Clinical findings. The fibrogenic role of ANGII in humans has been investigated in three recent prospective trials of limited size using biopsyproved myocardial fibrosis in patients with essential hypertension and LVH. Schwartzkopff et al [28] studied 14 patients before and after 1 year of treatment with the ACE inhibitor perindopril. Structural analysis revealed diminution of perivascular and interstitial fibrosis with treatment. The observed regression of fibrosis on ACE inhibitor treatment was observed in the non-pressure-overloaded right ventricle, indicating that the antifibrotic effect was not accounted for by left ventricular pressure reduction alone. Brilla et al [29] randomized 35 previously treated patients with controlled blood pressure to receive either the ACE inhibitor lisinopril or the diuretic hydrochlorothiazide for 6 months. Only patients randomized to lisinopril 
had a significant reduction in myocardial fibrosis. Blood pressure reduction was similar in patients treated with either lisinopril or hydrochlorothiazide. Finally, López et al [36] studied 37 treated patients with uncontrolled blood pressure. After randomization, 21 patients were assigned to the $\mathrm{AT}_{1}$ receptor antagonist losartan and 16 to the calcium channel blocker amlodipine for 12 months. Whereas myocardial fibrosis decreased significantly in losartantreated patients, this parameter remained unchanged in amlodipine-treated patients. A similar reduction of blood pressure in losartan-treated patients than in amlodipine-treated patients was reported in this study. Collectively, these observations support the concept that in addition to pressure overload, ANGII induces myocardial fibrosis in essential hypertension.

\section{Cellular and molecular mechanisms}

Increasing evidence strongly indicates that ANGII exerts multiple profibrotic effects within the heart including induction of fibroblast hyperplasia, activation of collagen biosynthetic pathways, and inhibition of collagen degradative pathways (Fig. 2). In addition, available data indicate that these effects may result from either the direct action of ANGII or a synergistic cooperation between this peptide and other profibrotic factors.

\section{Stimulation of fibroblast proliferation}

In vitro studies of rat and human cardiac fibroblasts have shown that ANGII stimulates cell proliferation by the $\mathrm{AT}_{1}$ receptor [54]. Results in the literature indicate that the proliferative response of fibroblasts to ANGII might well be mediated by stimulation of the synthesis of growth or inflammatory substances like platelet-derived growth factor and cytokines, by integrin activation caused by adhesion proteins, or by a combination of these mechanisms $[55,56]$.

For instance, ANGII strongly up-regulates the expression of osteopontin and its ligand $\alpha \mathrm{V} \beta 3$ integrin in rat and human cardiac cells [57,58]. Interestingly, elevated left ventricular osteopontin expression has been reported in the Ren2 rat model characterized by high myocardial ANGII concentrations [49]. Monoclonal antibodies directed against either osteopontin or $\alpha \mathrm{V} \beta 3$ completely blocked the mitogenic effect of ANGII on cultured rat

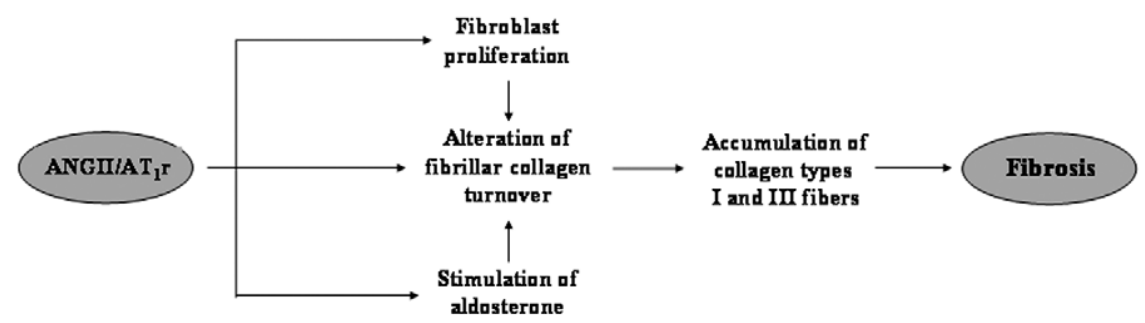

Fig. 2. Potential pathways involved in angiotensin II (ANG II)-mediated fibrosis. 
cardiac fibroblasts [58], suggesting that osteopontin mediates ANGII-induced fibroblast proliferation acting by an integrin-dependent pathway.

\section{Stimulation of collagen synthesis}

Although different signaling pathways of the $\mathrm{AT}_{1}$ receptor may subserve direct ANGII-induced collagen synthesis in cardiac fibroblasts [59], recent data suggest that the MAP/ER kinase pathway seems to play a major role [60]. The end result of signaling mechanisms is activation of transcription factors, which bind to various cis-acting elements in the regulatory sequences of $\alpha 1$ and $\alpha 2$ collagen type I and $\alpha 1$ collagen type III genes [60,61]. This, in turn, couples with gene expression and the synthesis of collagen types I and III precursor molecules [62,63].

A number of studies, however, provide strong evidence that ANGII indirectly regulates collagen synthesis by cardiac fibroblasts by specific growth factors [64]. The principal candidates include TGF- $\beta_{1}$ and endothelin-1.

In fact, ANGII has been shown to induce collagen type I gene expression by activation of TGF- $\beta_{1}$ signaling pathways (eg, connective tissue growth factor and Smad proteins) and these effects were blocked by the $\mathrm{AT}_{1}$ receptor antagonist losartan [65]. ANGII has been also shown to increase the expression of TGF- $\beta_{1}$ in cultured cardiac fibroblasts by stimulation of the $\mathrm{AT}_{1}$ [54]. Recent data suggest that a Krüppel-like zinc-finger transcription factor 5 (also known as BTEB2 and IKLF) is critically involved in ANGIIinduced TGF- $\beta_{1}$ expression, collagen synthesis, and development of cardiac fibrosis [66]. Besides up-regulation of cardiac gene TGF- $\beta_{1}$ expression, ANGII has been reported to convert latent TGF- $\beta_{1}$ to the active protein in vivo in the heart [67].

Endothelin-1 is synthesized and released by cardiac fibroblasts in response to the interaction of ANGII with the $\mathrm{AT}_{1}$ receptor [68] and has been shown to stimulate the synthesis of collagen types I and III in these cells [69]. In several rat models of arterial hypertension, blockade of endothelin receptors is associated with decrease in left ventricular collagen accumulation [70,71].

There is some in vivo evidence that ANGII also influences posttranslational processing of cardiac fibrillar collagen. It has been shown that ANGII infusion is associated with stimulation of prolyl 4-hydroxylase (an enzyme that mediates hydroxylation of procollagen $\alpha$ chains in the endoplasmic reticulum of cardiac fibroblasts) in the rat left ventricle [72]. In addition, it has been reported that immunoreactive prolyl 4-hydroxylase concentration decreases significantly in the ventricle of post-myocardial infarction rats treated with the $\mathrm{AT}_{1}$ receptor antagonist losartan [73].

\section{Inhibition of collagen degradation}

In addition to collagen synthesis, ANGII stimulation of the $\mathrm{AT}_{1}$ receptor has been shown to regulate collagen degradation by attenuating interstitial collagenase activity in adult rat [54] and human [74] cardiac fibroblasts and by enhancing TIMP-1 production in rat heart endothelial cells [75]. 
A number of factors may mediate the inhibitory effect of ANGII on cardiac collagen degradation (eg, TGF- $\beta_{1}$ and plasminogen activator inhibitor-1). Cell culture studies on human fibroblasts show that exposure of these cells to TGF- $\beta_{1}$ in the presence of other growth factors (eg, epidermal growth factor and basic fibroblastic growth factor) resulted in downregulation of collagenase and up-regulation of TIMP-1 [76,77]. Similar findings have been reported in the fibrotic myocardium of TGF- $\beta_{1}$ transgenic mice [78].

Activation of the $\mathrm{AT}_{1}$ receptor in human cardiac fibroblasts has been shown to promote stimulation of plasminogen activator inhibitor-1 expression [79]. This stimulatory effect has been confirmed in the left ventricle of ANGII-induced hypertensive rats [80]. Plasminogen activator inhibitor-1 inhibits the activation of collagenase and other matrix metalloproteinases and thereby collagen degradation $[81,82]$.

\section{Interaction with aldosterone}

Experimental studies have demonstrated the central role of aldosterone in promoting cardiac fibrosis, probably through a direct action on the heart mediated by cardiac mineralocorticoid receptors [83-85]. In fact, aldosterone has been shown to stimulate collagen synthesis through the mineralocorticoid receptor in isolated cardiac fibroblasts [86]. In experimental studies on rats with renovascular hypertension, hyperaldosteronism, or spontaneous hypertension, however, the aldosterone antagonist spironolactone was able to prevent or reverse the development of myocardial fibrosis even though the drug did not normalize blood pressure and did not prevent LVH [8,43,87-89]. An increase in this mineralocorticoid may be a mechanism for ANGII-induced cardiac fibrosis in some forms of arterial hypertension.

Interestingly, an increase in the density of $\mathrm{AT}_{1}$ receptors has been observed in the heart of aldosterone-salt-treated rats [90]. In addition, the $\mathrm{AT}_{1}$ receptor antagonist losartan prevents fibrosis and up-regulation of collagen types I and III mRNAs in the heart of aldosterone-salt-treated rats [91]. Taken together, these findings support the hypothesis that one mechanism by which aldosterone induces cardiac fibrosis involves ANGII acting through $\mathrm{AT}_{1}$ receptors. Because the production of aldosterone is activated in the hypertrophied left ventricle of rats with spontaneous hypertension [92] and hypertensive patients [93], it is possible that aldosterone contributes to ANGII-mediated myocardial fibrosis in primary hypertension.

The potential clinical relevance of these interactions is given by several observations. In essential hypertension, a low dose of the aldosterone antagonist canrenone added to antihypertensive treatment has been shown significantly to improve left ventricular diastolic function [94]. This improvement, not accounted for by changes in blood pressure and left ventricular mass, can be ascribed to a direct action of the drug on the myocardium. This is further supported by recent studies showing that chronic administration 
of either spironolactone [95-99] or potassium canrenoate [100] is associated with a reduction in the circulating levels of markers of collagen turnover in patients with different cardiac diseases that evolve with myocardial fibrosis.

\section{Summary}

Structural homogeneity of cardiac tissue is governed by mechanical and humoral factors that regulate cell growth, apoptosis, phenotype, and extracellular matrix turnover. ANGII has endocrine, autocrine, and paracrine properties that influence the behavior of cardiac cells and matrix by $\mathrm{AT}_{1}$ receptor binding. Various paradigms have been suggested, including ANGIImediated up-regulation of collagen types I and III formation and deposition in cardiac conditions, such as HHD. A growing body of evidence, however, deals with the potential role of aldosterone, either local or systemic, in inducing cardiac fibrosis. Aldosterone might also mediate the profibrotic actions of ANGII. To reduce the risk of heart failure that accompanies HHD, its adverse structural remodeling (eg, myocardial hypertrophy and fibrosis) must be targeted for pharmacologic intervention. Cardioprotective agents must reverse not only the exaggerated growth of cardiac cells, but also regress existing abnormalities in fibrillar collagen. Available experimental and clinical data suggest that agents interfering with $\mathrm{ACE}$, the $\mathrm{AT}_{1}$ receptor, or the mineralocorticoid receptor may provide such a cardioprotective effect.

\section{References}

[1] Weber KT. Fibrosis, a common pathway to organ failure: angiotensin II and tissue repair. Semin Nephrol 1997;17:467-91.

[2] Tan LB, Jalil JE, Pick R, Janicki JS, Weber KT. Cardiac myocyte necrosis induced by angiotensin II. Circ Res 1991;69:1185-95.

[3] Benjamin IJ, Jalil JE, Tan LB, Cho K, Weber KT, Clark WA. Isoproterenol-induced myocardial fibrosis in relation to myocyte necrosis. Circ Res 1989;65:657-70.

[4] Ratajska A, Campbell SE, Sun Y, Weber KT. Angiotensin II associated cardiac myocyte necrosis: role of adrenal catecholamines. Cardiovasc Res 1994;28:684-90.

[5] Sun Y, Cleutjens JP, Diaz-Arias AA, Weber KT. Cardiac angiotensin converting enzyme and myocardial fibrosis in the rat. Cardiovasc Res 1994;28:1423-32.

[6] Jugdutt BI, Amy RW. Healing after myocardial infarction in the dog: changes in infarct hydroxyproline and topography. J Am Coll Cardiol 1986;7:91-102.

[7] Weber KT, Brilla CG. Pathological hypertrophy and cardiac interstitium: fibrosis and renin-angiotensin-aldosterone system. Circulation 1991;83:1849-65.

[8] Brilla CG, Pick R, Tan LB, Janicki JS, Weber KT. Remodeling of the rat right and left ventricles in experimental hypertension. Circ Res 1990;67:1355-64.

[9] Sun Y, Ratajska A, Zhou G, Weber KT. Angiotensin-converting enzyme and myocardial fibrosis in the rat receiving angiotensin II or aldosterone. J Lab Clin Med 1993;122: 395-403.

[10] Goldblatt H. Experimental hypertension induced by renal ischemia (Harvey Lecture). Bull N Y Acad Med 1938;14:523-53.

[11] Hall CE, Hall O. Hypertension and hypersalimentation. I. Aldosterone hypertension. Lab Invest 1965;14:285-94. 
[12] Weber KT. Cardiac interstitium in health and disease: the fibrillar collagen network. J Am Coll Cardiol 1989;13:1637-52.

[13] Weber KT. Stroma and the search for common ground. Plumbism or promiscuity? Cardiovase Res 1995;29:330-5.

[14] Müller GA, Schettler V, Müller CA, Strutz F. Prevention of progression of renal fibrosis: How far are we? Kidney Int 1996;49(suppl 54):S75-82.

[15] Eddy AA. Interstitial macrophages as mediators of renal fibrosis. Exp Nephrol 1995;3: 76-9.

[16] Adler KB, Low RB, Leslie KO, Mitchell J, Evans JN. Biology of disease: contractile cells in normal and fibrotic lung. Lab Invest 1989;60:473-85.

[17] Dunnill MS. Pulmonary fibrosis. Histopathology 1990;16:321-9.

[18] Friedman SL. Seminars in medicine of the Beth Israel Hospital, Boston. The cellular basis of hepatic fibrosis: mechanisms and treatment strategies. N Engl J Med 1993;328:1828-35.

[19] Pérez-Tamayo R. Collagen resorption in carrageenin granulomas. I. Collagenolytic activity in in vitro explants. Lab Invest 1970;22:137-41.

[20] Kuncio GS, Neilson EG, Haverty T. Mechanisms of tubulointerstitial fibrosis. Kidney Int 1991;39:550-6.

[21] Strutz F, Müller GA. On the progression of chronic renal disease. Nephron 1995;69: $371-9$.

[22] Weber KT, Sun Y, Campbell SE, Slight SH, Ganjam VK, Griffing GT, et al. Chronic mineralocorticoid excess and cardiovascular remodeling. Steroids 1995;60:125-32.

[23] Beltrami CA, Finato N, Rocco M, Feruglio GA, Puricelli C, Cigola E, et al. Structural basis of end-stage failure in ischemic cardiomyopathy in humans. Circulation 1994;89:151-63.

[24] Tanaka M, Fujiwara H, Onodera T, Wu DJ, Hamashima Y, Kawai C. Quantitative analysis of myocardial fibrosis in normals, hypertensive hearts, and hypertrophic cardiomyopathy. Br Heart J 1986;55:575-81.

[25] Olivetti G, Melissari M, Balbi T, Quaini F, Cigola E, Sonnenblick EH, et al. Myocyte cellular hypertrophy is responsible for ventricular remodelling in the hypertrophied heart of middle aged individuals in the absence of cardiac failure. Cardiovasc Res 1994;28:1199-208.

[26] Rossi MA. Pathologic fibrosis and connective tissue matrix in left ventricular hypertrophy due to chronic arterial hypertension in humans. J Hypertens 1998;16:1031-41.

[27] Ciulla M, Paliotti R, Hess DB, Tjhja E, Campbell SE, Magrini F, et al. Echocardiographic patterns of myocardial fibrosis in hypertensive patients: endomyocardial biopsy versus ultrasonic tissue characterization. J Am Soc Echocardiogr 1997;10:657-64.

[28] Schwartzkopff B, Brehm M, Mundehenke M, Strauer BE. Repair of coronary arterioles after treatment with perindopril in hypertensive heart disease. Hypertension 2000;36:220-5.

[29] Brilla CG, Funck RC, Rupp RH. Lisinopril-mediated regression of myocardial fibrosis in patients with hypertensive heart disease. Circulation 2000;102:1388-93.

[30] Querejeta R, Varo N, López B, Larman M, Artiñano E, Etayo JC, et al. Serum carboxyterminal propeptide of procollagen type $\mathrm{I}$ is a marker of myocardial fibrosis in hypertensive heart disease. Circulation 2000;101:1729-35.

[31] Pardo-Mindán FJ, Panizo A. Alterations in extracellular matrix of the myocardium in essential hypertension. Eur Heart J 1993;14(suppl J):12-4.

[32] Burlew BS, Weber KT. Connective tissue and the heart: functional significance and regulatory mechanisms. Cardiol Clin 2000;18:435-42.

[33] Bishop JE, Lindahl G. Regulation of cardiovascular collagen synthesis by mechanical load. Cardiovasc Res 1999;42:27-44.

[34] Amanuma S, Sekiguchi M, Ogasawara S, Honda M, Hosoda S. Biventricular endomyocardial biopsy findings in essential hypertension of graded severity. Postgrad Med J 1994;70(suppl 1):S67-71.

[35] Pearlman ES, Weber KT, Janicki JS, Pietra GG, Fishman AP. Muscle fiber orientation and connective tissue content in the hypertrophied human heart. Lab Invest 1982;46:158-64. 
[36] López B, Querejeta R, Varo N, González A, Larman M, Martínez Ubago JL, et al. Usefulness of serum carboxy-terminal propeptide of procollagen type I in assessment of the cardioreparative ability of antihypertensive treatment in hypertensive patients. Circulation 2001;104:286-91.

[37] Weber KT. Fibrosis and hypertensive heart disease. Curr Opin Cardiol 2000;15:264-72.

[38] Díez J, López B, González A, Querejeta R. Clinical aspects of hypertensive myocardial fibrosis. Curr Opin Cardiol 2001;16:328-35.

[39] Sun Y, Ramires FJA, Weber KT. Fibrosis of atria and great vessels in response to angiotensin II or aldosterone infusion. Cardiovasc Res 1997;35:138-47.

[40] Jalil JE, Janicki JS, Pick R, Weber KT. Coronary vascular remodeling and myocardial fibrosis in the rat with renovascular hypertension: response to captopril. Am J Hypertens 1991;4:51-5.

[41] Everett AD, Tufro-Mcreddie A, Fisher A, Gomez RA. Angiotensin receptor regulates cardiac hypertrophy and transforming growth factor- $\beta 1$ expression. Hypertension 1994; 23:587-92.

[42] Campbell JE, Janicki JS, Weber KT. Temporal differences in fibroblast proliferation and phenotype expression in response to chronic administration of angiotensin II or aldosterone. J Mol Cell Cardiol 1995;27:1545-60.

[43] Brilla CG, Matsubara LS, Weber KT. Anti-aldosterone treatment and the prevention of myocardial fibrosis in primary and secondary aldosteronism. J Mol Cell Cardiol 1993;25: $563-75$.

[44] Kim S, Ohta K, Hamaguchi A, Yukimura T, Miura K, Iwao H. Angiotensin II-induced cardiac phenotypic modulation and remodeling in vivo in rats. Hypertension 1995;25: $1252-9$.

[45] Crawford DC, Chobanian AV, Brecher P. Angiotensin II induces fibronectin expression associated with cardiac fibrosis in the rat. Circ Res 1994;74:727-39.

[46] Lee MA, Bohm M, Paul M, Bader M, Ganten U, Ganten D. Physiological characterization of the hypertensive transgenic rat TGR(mREN2)27. Am J Physiol 1996;270: E919-29.

[47] Bishop JE, Kiernan LA, Montgomery HE, Gohlke P, Mcewan JR. Raised blood pressure, not renin-angiotensin systems, causes cardiac fibrosis in TGR m(Ren2)27 rats. Cardiovasc Res 2000;47:57-67.

[48] Pinto YM, Pinto-Sietsma SJ, Philipp T, Engler S, Kossmehl P, Hocher B, et al. Reduction in left ventricular messenger RNA for transforming growth factor beta (1) attenuates left ventricular fibrosis and improves survival without lowering blood pressure in the hypertensive TGR(mRen2)27 rat. Hypertension 2000;36:747-54.

[49] Rothermund L, Kreutz R, Kossmehl P, Fredersdorf S, Shakibaei M, Schulze-Tamzil G, et al. Early onset of chondroitin sulfate and osteopontin expression in angiotensin IIdependent left ventricular hypertrophy. Am J Hypertens 2002;15:644-52.

[50] Teisman AC, Pinto YM, Buikema H, Flesch M, Bohm M, Paul M, et al. Dissociation of blood pressure reduction from end-organ damage in TGR(mREN2)27 transgenic hypertensive rats. J Hypertens 1998;16:1759-65.

[51] Brilla CG, Janicki JS, Weber KT. Impaired diastolic function and coronary reserve in genetic hypertension: role of interstitial fibrosis and medial thickening of intramyocardial coronary arteries. Circ Res 1991;69:107-15.

[52] Varo N, Etayo JC, Zalba G, Beaumont J, Iraburu MJ, Montiel C, et al. Losartan inhibits the postranscriptional synthesis of collagen type I and reverses left ventricular fibrosis in spontaneously hypertensive rats. J Hypertens 1999;17:101-14.

[53] Varo N, Iraburu M, Varela M, López B, Etayo JC, Díez J. Chronic AT 1 blockade stimulates extracellular collagen type I degradation and reverses myocardial fibrosis in spontaneously hypertensive rats. Hypertension 2000;35:1197-202.

[54] Sadoshima J, Izumo S. Molecular characterization of angiotensin II-induced hypertrophy of cardiac myocytes and hyperplasia of cardiac fibroblasts. Circ Res 1993;73:413-23. 
[55] Bouzegrhane F, Thibault G. Is angiotensin II a proliferative factor of cardiac fibroblasts? Cardiovasc Res 2002;53:304-12.

[56] Schnee JM, Hsueh WA. Angiotensin II, adhesion, and cardiac fibrosis. Cardiovasc Res 2000;46:264-8.

[57] Graf K, Neuss M, Stawowy P, Hsueh WA, Pleck E, Law RE. Angiotensin II and alpha(V)beta(3) integrin expression in rat neonatal cardiac fibroblasts. Hypertension 2000;35:978-84.

[58] Ashizawa N, Graf K, Do YS, Nunohiro T, Giachelli CM, Meehan WP, et al. Osteopontin is produced by rat cardiac fibroblasts and mediates AII-induced DNA synthesis and collagen gel contraction. J Clin Invest 1996;98:2218-27.

[59] Dostal DE, Booz GW, Baker KM. Angiotensin II signaling pathways in cardiac fibroblasts: conventional versus novel mechanisms in mediating cardiac growth and function. Mol Cell Biochem 1996;157:15-21.

[60] Tharaux PL, Chatziantoniou C, Fakhouri F, Dussaule JC. Angiotensin II activates collagen I gene through a mechanism involving the MAP/ER kinase pathway. Hypertension 2000;36:330-6.

[61] Ghiggeri GM, Oleggini R, Musante L, Garidi G, Gusmano R, Ravazzolo R. A DNA element in the al type III collagen promoter mediates a stimulatory response by angiotensin II. Kidney Int 2000;58:537-48.

[62] Crabos M, Roth M, Hahn AW, Erne P. Characterization of angiotensin II receptors in cultured adult rat cardiac fibroblasts: coupling to signaling systems and gene expression. J Clin Invest 1994;93:2372-8.

[63] Villarreal FJ, Kim NN, Ungab GD, Printz MP, Dillmann WH. Identification of functional angiotensin II receptors on cardiac fibroblasts. Circulation 1993;88:2849-61.

[64] Dostal DE. Regulation of cardiac collagen: angiotensin and cross-talk with local growth factors. Hypertension 2001;37:841-4.

[65] Hao J, Wang B, Jones SC, Jassal DS, Dixon IM. Interaction between angiotensin II and Smad proteins in fibroblasts in failing heart and in vitro. Am J Physiol 2000;279: H3020-30.

[66] Shindo T, Manabe I, Fukushima Y, Tobe K, Aizawa K, Miyamoto S, et al. Krüppel-like zinc-finger transcription factor KLF5/BTEB2 is a target for angiotensin II signaling and an essential regulator of cardiovascular remodeling. Nat Med 2002;8:856-63.

[67] Tomita H, Egahsira K, Ohara Y, Takemoto M, Koyanagi M, Katoh M, et al. Early induction of transforming growth factor- $\beta$ via angiotensin II type 1 receptors contributes to cardiac fibrosis induced by long-term blockade of nitric oxide synthesis in rats. Hypertension 1998;32:273-9.

[68] Gray MO, Long CS, Kalinyak JE, Li HT, Karliner JS. Angiotensin II stimulates cardiac myocyte hypertrophy via paracrine release of TGF-beta 1 and endothelin- 1 from fibroblasts. Cardiovasc Res 1998;40:352-63.

[69] Guarda E, Katwa LC, Myers PR, Tyagi SC, Weber KT. Effects of endothelins on collagen turnover in cardiac fibroblasts. Cardiovasc Res 1993;27:2130-4.

[70] Ammarguellat F, Larouche II, Schiffrin EL. Myocardial fibrosis in DOCA-salt hypertensive rats: effect of endothelin (ETA) receptor antagonism. Circulation 2001;103: 319-24.

[71] Yamamoto K, Masuyama T, Sakata Y, Nishikawa N, Mano T, Hori M. Prevention of diastolic heart failure by endothelin type A receptor antagonist through inhibition of ventricular structural remodeling in hypertensive heart. J Hypertens 2002;20:753-61.

[72] Leipala JA, Takala TE, Ruskoaho H, Myllyla R, Kainulainen H, Hassinen IE, et al. Transmural distribution of biochemical markers of total protein and collagen synthesis, myocardial contraction speed and capillary density in the rat left ventricle in angiotensin II-induced hypertension. Acta Physiol Scand 1988;133:325-33.

[73] Ju H, Zhao S, Jassal DS, Dixon IM. Effect of AT1 receptor blockade on cardiac collagen remodeling after myocardial infarction. Cardiovasc Res 1997;35:223-32. 
[74] Funck RC, Wilke A, Rupp H, Brilla CG. Regulation and role of myocardial matrix remodeling in hypertensive heart disease. Adv Exp Mol Biol 1997;432:35-44.

[75] Chua CH, Hamdy RC, Chua BH. Angiotensin II induces TIMP-1 production in rat heart endothelial cells. Biochem Biophys Acta 1996;1311:175-80.

[76] Edwards DR, Murphy G, Reynolds JJ, Whitham SE, Docherty AJ, Angel P, et al. Transforming growth factor beta modulates the expression of collagenase and metalloproteinase inhibitor. EMBO J 1987;6:1899-904.

[77] Chua CC, Chua BH, Zhao ZY, Krebs C, Diglio C, Perrin E. Effect of growth factors on collagen metabolism in cultured human heart fibroblasts. Connect Tissue Res 1991;26: $271-81$.

[78] Seeland U, Haeuseler C, Hinrichs R, Rosenkranz S, Pfitzner T, Scharffetter-Kochanek K, et al. Myocardial fibrosis in transforming growth factor- $\beta_{1}$ (TGF- $\left.\beta_{1}\right)$ transgenic mice is associated with inhibition of interstitial collagenase. Eur J Clin Invest 2002;32: 295-303.

[79] Kawano H, Do YS, Kawano Y, Starnes V, Barr M, Law RE, et al. Angiotensin II has multiple profibrotic effects in human cardiac fibroblasts. Circulation 2000;101:1130-7.

[80] Kobayashi N, Nakano S, Mita S, Kobayashi T, Honda T, Tsubokou Y, et al. Involvement of Rho-kinase pathway for angiotensin II-induced plasminogen activator inhibitor-1 gene expression and cardiovascular remodeling in hypertensive rats. J Pharmacol Exp Ther 2002;301:459-66.

[81] Yamamoto K, Saito H. A pathological role of increased expression of plasminogen activator inhibitor-1 in human or animal disorders. Int J Hematol 1998;68:371-85.

[82] Dollery CM, Mcewan JR, Henney AM. Matrix metalloproteinases and cardiovascular diseases. Circ Res 1995;77:863-8.

[83] Weber KT, Sun Y, Guarda E. Structural remodeling in hypertensive heart disease and the role of hormones. Hypertension 1994;23:869-77.

[84] Young M, Fullerton M, Dilley R, Funder J. Mineralocorticoids, hypertension, and cardiac fibrosis. J Clin Invest 1994;93:2578-83.

[85] Lombes M, Alfaidy N, Eugene E, Lessana A, Farman N, Bonvalet JP. Prerequisite for cardiac aldosterone action: mineralocorticoid receptor and 11 beta-hydroxysteroid dehydrogenase in the human heart. Circulation 1995;92:175-82.

[86] Brilla CG, Zhou G, Matsubara L, Weber KT. Collagen metabolism in cultured adult rat cardiac fibroblasts: response to angiotensin II and aldosterone. J Mol Cell Cardiol 1994; 26:809-20.

[87] Brilla CG, Matsubara LS, Weber KT. Antifibrotic effects of spironolactone in preventing myocardial fibrosis in systemic arterial hypertension. Am J Cardiol 1993;71:12A-6A.

[88] Nicoletti A, Heudes D, Hinglais N, Appay MD, Philippe M, Sassy-Prigent C, et al. Left ventricular fibrosis in renovascular hypertensive rats: effect of losartan and spironolactone. Hypertension 1995;26:101-11.

[89] Lacolley P, Safar ME, Lucet B, Ledudal K, Labat C, Benetos A. Prevention of aortic and cardiac fibrosis by spironolactone in old normotensive rats. J Am Coll Cardiol 2001;37: $662-7$.

[90] Sun Y, Weber KT. Ang II and aldosterone receptor binding in rat heart and kidney: response to chronic angiotensin II or aldosterone. J Lab Clin Med 1993;122:404-11.

[91] Robert V, Heymes C, Silvestre JS, Sabri A, Swynghedauw B, Delcayre C. Angiotensin $\mathrm{AT}_{1}$ receptor subtype as a cardiac target of aldosterone: role in aldosterone-salt-induced fibrosis. Hypertension 1999;33:981-6.

[92] Takeda Y, Yoneda T, Demure M, Miyamori I, Mabuchi H. Cardiac aldosterone production in genetically hypertensive rats. Hypertension 2000;36:495-500.

[93] Yamamoto N, Yasue H, Mizuno Y, Yoshimura M, Fujii H, Nakayama M, et al. Aldosterone is produced from ventricles in patients with essential hypertension. Hypertension 2002;39:958-62. 
[94] Grandi AM, Imperiale D, Santillo R, Barlocco E, Bertolini A, Guasti L, et al. Aldosterone antagonist improves diastolic function in essential hypertension. Hypertension 2002;40:647-52.

[95] MacFadyen RJ, Barr CS, Struthers AD. Aldosterone blockade reduces vascular collagen turnover, improves heart rate variability and reduces early morning rise in heart rate in heart failure patients. Cardiovasc Res 1997;35:30-4.

[96] Zannad F, Alla F, Dousset B, Perez A, Pitt B. Limitation of excessive extracellular matrix turnover may contribute to survival benefit of spironolactone therapy in patients with congestive heart failure: insights from the randomized aldactone evaluation study (RALES). Rales Investigators. Circulation 2000;102:2700-6.

[97] Tsutamoto T, Wada A, Maeda K, Mabuchi N, Hayashi M, Tsutsui T, et al. Spironolactone inhibits the transcardiac extraction of aldosterone in patients with congestive heart failure. J Am Coll Cardiol 2000;36:838-44.

[98] Hayashi M, Tsutamoto T, Wada A, Maeda K, Mabuchi N, Tsutsui T, et al. Relationship between transcardiac extraction of aldosterone and left ventricular remodeling in patients with first acute myocardial infarction: extracting aldosterone through the heart promotes ventricular remodeling after acute myocardial infarction. J Am Coll Cardiol 2001;38:1375-82.

[99] Hayashi M, Tsutamoto T, Wada A, Tsutsui T, Ishii C, Ohno K, et al. Immediate administration of mineralocorticoid receptor antagonist spironolactone prevents postinfarct left ventricular remodeling associated with suppression of a marker of myocardial collagen synthesis in patients with first anterior acute myocardial infarction. Circulation 2003;107:2559-65.

[100] Modena MG, Aveta P, Menozzi A, Rossi R. Aldosterone inhibition limits collagen synthesis and progressive left ventricular enlargement after anterior myocardial infarction. Am Heart J 2001;141:41-6. 